\title{
FUNDO DE GARANTIA POR TEMPO DE SERVIÇO (FGTS) - EM BUSCA DA CORREÇÃO "JUSTA"
}

\section{ROCCO ANTONIO RANGEL ROSSO NELSON}

MARCOS VASCONCELOS CORREIA

INSTITUTO FEDERAL DO RIO GRANDE DO NORTE - IFRN CAMPUS JOÃO CÂMARA

$B R A S I L$ 


\begin{tabular}{c}
\hline ROCCO ANTONIO RANGEL ROSSO NELSON - MARCOS VASCONCELOS CORREIA \\
FUNDO DE GARANTIA POR TEMPO DE SERVIÇO (FGTS) - EM BUSCA DA CORREÇÃO “JUSTA”. \\
Pags. 146 - 163 \\
\hline
\end{tabular}

Recibido: 06/11/2014

Aceptado: 29/04/2015

\title{
RESUMO
}

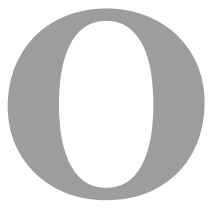

direito social fundamental referente ao fundo de garantia por tempo de serviço (FGTS) adentra as pautas de discussões atuais do direito, sendo reforçado pela exposição midiática, tendo em vista o pleito de que os saldos do FGTS sejam corrigidos em face de um índice oficial que refletisse a inflação, como o INPC (índice nacional de preços ao consumidor), referente a depósitos entre 1999 até os dias atuais, ao invés da correção feita baseada na Taxa referencial (TR). A presente demanda abarrotou a justiça brasileira, ganhando a contenda esteira no STJ e STF. A importância da matéria é palmar, tendo em vista que a posição a ser tomada afetaria 45 milhões de trabalhadores. A pesquisa em tela, fazendo uso de uma metodologia de análise qualitativa, usando-se os métodos de abordagem hipotético-dedutivos de caráter descritivo e analítico, tem por escopo analisar a questão sobre a correção atuarial dos valores depositados a título de fundo de garantia por tempo de serviço. Com fulcro no direito da propriedade, tendo em vista que os saldos fundiários constituírem salário, na modalidade diferida, deve prosperar a tese da correção desses saldos por um índice que reflita a inflação.

Palavras-chave: direito do trabalhador, fundo de garantia por tempo de serviço (FGTS), correção, justiça.

\begin{abstract}
The fundamental social right related Guarantee Fund for Time of Service (FGTS) enters the guidelines of current discussions of law, reinforced by the media exposure, in view of the claim that the FGTS are corrected in the face of an official index reflect inflation, as the INPC (national consumer price index) related to deposits from 1999 to the present day, rather than the correction made based on the reference rate (TR). This demand crammed Brazilian courts, winning the contest in the wake STJ and STF. The significance of the matter is blatant in order that the position to be taken affect 45 million people. Research on screen, using a methodology of qualitative analysis, using the hypothetical-deductive methods of descriptive and analytical approach to character is scope to examine the question on actuarial correction of amounts deposited as a guarantee fund for service time. With based property rights, given that the land balances constitute salary in deferred mode, the thesis must thrive correction of these balances by an index that reflects inflation.
\end{abstract}

Keyword: worker's right, guarantee fund for time of service (FGTS), correction, justice. 


\section{RESUMEN}

Los derechos sociales fundamentales con respecto al Fondo de Garantía por Tiempo de Servicio (FGTS) entra en las pautas de las discusiones actuales de la ley, siendo reforzados por exposición a los medios, en vista de las elecciones que los FGTS se corrigen en la cara de un índice oficial para reflejar la inflación, ya que el INPC (índice de precios al consumidor nacional) en relación con los depósitos a partir de 1999 hasta nuestros días, en lugar de la corrección realizada a partir de la tasa de referencia (TR). Esta demanda abarrota los tribunales brasileños, alcanzando el Superior Tribunal de Justiça (STJ) y el Superior Tribunal Federal (STF). La importancia de la materia, por supuesto, teniendo en cuenta que la posición que debe adoptar afecta a 45 millones de trabajadores. Investigación en la pantalla, haciendo uso de un método de análisis cualitativo, utilizando los métodos hipotético-deductivos de enfoque descriptivo y analítico de carácter se alcance a examinar la cuestión en la corrección actuarial del valor del depósito en un fondo de garantía para el tiempo de servicio. Con el punto de apoyo en el derecho de propiedad, con el fin de que las ventas de tierras constituyen salario en modo diferido, la tesis debe prosperar la corrección de dichos saldos por un índice que refleja la inflación.

Palabras Clave: los derechos de los trabajadores, fondo de garantía por tiempo de servicio (FGTS), corrección, justicia.

\section{DAS CONSIDERAÇÕES INICIAIS}

O fundo de garantia por tempo de serviço - FGTS - foi institucionalizado por meio da Lei $\mathrm{n}^{\mathrm{o}}$ 5.107/66 e constituiu-se numa alternativa ao regime de estabilidade decenal previsto no art. 492 da Consolidação das Leis do Trabalho - CLT ${ }^{1}$. Com a Constituição Federal de 1967, em seu art. 158, XIII², houve a constitucionalização do regime fundiário.

Sobre a criação do FGTS, assim explicita o professor Delgado (2011):

Criado pela Lei n. 5.107, de 1966, inicialmente como sistema alternativo ao indenizatório e estabilitário da CLT, o FGTS submetia-se a uma opção escrita por parte do trabalhador, no início do contrato laborativo. A nova lei facultava

\footnotetext{
${ }^{1}$ CLT. Art. 492 - O empregado que contar mais de 10 (dez) anos de serviço na mesma empresa não poderá ser despedido senão por motivo de falta grave ou circunstância de força maior, devidamente comprovadas.

${ }^{2}$ Constituição Federal de 1967. Art. 158 - A Constituição assegura aos trabalhadores os seguintes direitos, além de outros que, nos termos da lei, visem à melhoria, de sua condição social: (...) XIII - estabilidade, com indenização ao trabalhador despedido, ou fundo de garantia equivalente;
} 


\begin{tabular}{c}
\hline ROCCO ANTONIO RANGEL ROSSO NELSON - MARCOS VASCONCELOS CORREIA \\
$150<\quad$ FUNDO DE GARANTIA POR TEMPO DE SERVIÇO (FGTS) - EM BUSCA DA CORREÇÃO “JUSTA”. \\
Pags. $146-163$ \\
\hline
\end{tabular}

também a realização de opção retroativa ao longo do contrato ainda não inserido no sistema do Fundo de Garantia. (p. 1206).

Com o advento da Constituição cidadã, o regime do FGTS torna-se único, universalizando o sistema fundiário ${ }^{3}$, tanto para trabalhadores urbanos e rurais, subsistindo, apenas, o direito adquirido a estabilidade decenal ao trabalhador que perfazia tal condição até da Constituição atual ${ }^{4}$.

Tal prescrição normativa encontra-se no enunciado redacional do art. 14 da Lei no 8.036/90:

Art. 14. Fica ressalvado o direito adquirido dos trabalhadores que, à data da promulgação da Constituição Federal de 1988, já tinham o direito à estabilidade no emprego nos termos do Capítulo V do Título IV da CLT.

No que tange a esse ao artigo supra, o professor Vilhena (1992) oferta critica impecável:

O dispositivo referido atesta o que se pode qualificar de soberba, ao asseverar que "fica ressalvado o direito adquirido dos trabalhadores ..." etc., como se às suas costas e por sobre a sua cabeça não estivesse em vigor ou inexistisse na pirâmide normativa o art. $5^{\circ}$, XXXVI, da Constituição nem a outra regra de sobre-direito (überrecht) do art. $6^{\circ}$ da Lei de Introdução ao Código Civil (Decreto n. ${ }^{\circ} 4.657$, de 4-9-42), que asseguram o direito adquirido e contra a própria lei. (pp. 169-170).

No que tange a sua natureza jurídica, a matéria encontra-se num certo limbo, estando longe de uma unanimidade.

Para o Superior Tribunal de Justiça, a partir da súmula nº 353 (As disposições do Código Tributário Nacional não se aplicam às contribuições para o FGTS), o FGTS não teria natureza tributária: "Pelo enunciado dessa súmula, afere-se que o STJ entende que o FGTS não tem natureza de tributo, de tal sorte, não se deve aplicar o regramento do Código Tributário Nacional, bem como as regras de execução fiscal" (Martins, 2005, p. 459).

Já para Martins (2005), teria natureza tributária: “Assim, entendemos que para o empregador o FGTS vem a ser uma contribuição social, espécie do gênero tributo. Não se

\footnotetext{
${ }^{3}$ CF/88. Art. 158 - A Constituição assegura aos trabalhadores os seguintes direitos, além de outros que, nos termos da lei, visem à melhoria, de sua condição social: (...) III - fundo de garantia do tempo de serviço;

4 “(...) Deverá, no entanto, ser respeitado o direito adquirido, na medida em que os empregados que na data da promulgação da Constituição Federal se submetiam às regras de estabilidade decenal não poderão ter substituído o regime para o Fundo de Garantia do Tempo de Serviço. (...)" (Canotilho, Leoncy, Mendes, Sarlet, \& Streck, 2013, p. 562). “É evidente que as pessoas que tinham direito adquirido à estabilidade, pois já contavam com mais de 10 anos no emprego em 4-10-88, não irão perdê-la com o direito ao FGTS a partir de 5-10-88. O próprio art. 14 da Lei no 8.036 ressalva essa questão" (Martins, 2005, p. 454).
} 
trata de outro tipo de contribuição ou de contribuição previdenciária, pois para nós esta tem natureza tributária, de contribuição social (...)” (p. 459).

Para fins desse ensaio, adotar-se-á a lição do professor Delgado (2011):

O FGTS é instituto de natureza multidimensional, complexa, com preponderante estrutura e fins justrabalhistas, os quais se combinam, porém, harmonicamente, a seu caráter de fundo social de destinação variada, tipificada em lei. Por isso associa traços de mera figura trabalhista com traços de figura afeta às contribuições sociais, formando, porém, instituto unitário (p. 1213).

Na esteira de Cassar (2011), a natureza do FGTS seria múltipla:

Para o empregado o FGTS tem natureza jurídica de direito à contribuição que tem caráter salarial (salário diferido). Equipara-se a uma poupança forçada. Para o empregador é uma obrigação e para a sociedade a contribuição tem caráter social. Daí decorre sua natureza múltipla ou híbrida (p. 1244).

É fato que com a instituição do FGTS, nos idos da década de sessenta, a figura da estabilidade decenal tornara-se rara, tendo em vista a prática do empregador em só contratar se o empregado optasse pelo respectivo FGTS, constituindo-se, assim, em uma das primeiras formas de flexibilização da relação de trabalho ${ }^{5}$, implantado no Brasil.

“A flexibilização tem sido voltada para o capital, para o aumento da produção. Visa maximizar lucros em decorrência da internacionalização das economias” (Martins, 2009, p. 09).

“(...) porquanto o empregado deveria manifestar, quando da contratação, sua opção pelo regime do Fundo de Garantia do Tempo de Serviço; mais do que uma opção, tornou-se condição de possibilidade da admissão, (...)” (Canotilho, Leoncy, Mendes, Sarlet, \& Streck, 2013, p. 562).

Segundo o art. $1^{\circ}$ da Lei $\mathrm{n}^{\circ} 5 \cdot 107 / 66$, visava o FGTS assegurar aos empregados uma garantia pelo tempo de serviço prestado às empresas, mediante opção do empregado. O referido sistema era compatível com a estabilidade decenal, porém o que ocorreu na prática é que nenhuma empresa admitia empregado se não fosse optante do FGTS, visando, assim, a que o empregado não adquirisse a estabilidade (Martins, 2005, p. 452).

\footnotetext{
5 "De fato, o ramo justrabalhista afirmou-se no período anterior como o mais clássico e abrangente instrumento de políticas sociais surgido no capitalismo, produzindo inquestionável intervenção normativa na economia, em favor, regra geral, de importante distribuição social dos ganhos do sistema econômico. Nesse contexto, a desregulamentação de suas regras ou, pelo menos, sua crescente flexibilização, tudo passou a compor foco destacado na matriz cultural que se generalizou no Ocidente no último quartel do século XX" (Delgado, 2011, p. 99).
} 


\begin{tabular}{c}
\hline ROCCO ANTONIO RANGEL ROSSO NELSON - MARCOS VASCONCELOS CORREIA \\
$152<\quad$ FUNDO DE GARANTIA POR TEMPO DE SERVIÇO (FGTS) - EM BUSCA DA CORREÇÃO “JUSTA”. \\
Pags. 146 - 163 \\
\hline
\end{tabular}

Nesses termos explicita o professor Vilhena (1992):

Como toda a abordagem experimental, a implantação do regime do FGTS pela Lei $\mathrm{n}^{\circ}$ " 5.107/66, foi tosca, para não dizer grosseira, pois logo se viu que a opção, formalmente ato do empregado, era, na realidade, dirigida pelo empregador e que, se na admissão ou em até um ano da vigência da lei, o empregado não optasse, ele somente poderia fazê-lo, e até com efeito retroativo, com o consentimento do empregador (p. 164).

Hoje, o FGTS tem seu regramento na Lei $n^{\circ} 8.036 / 90$, sendo regulado pelo decreto $\mathrm{n}^{\circ} 99.684 / 99$.

A forma de atualização dos valores depositados a título de FGTS, fora normatizado no art. 13 da Lei $n^{\circ} 8.036 / 90$, assim enunciado:

Art. 13. Os depósitos efetuados nas contas vinculadas serão corrigidos monetariamente com base nos parâmetros fixados para atualização dos saldos dos depósitos de poupança e capitalização juros de (três) por cento ao ano (Grifos nossos).

O artigo supra garante uma "remuneração" aos valores depositados, no fundo, de $3 \%$ ao ano e a correção monetária igual àquela aplicada aos depósitos referentes a poupança.

Com o processo de desindexação da economia, a Lei ${ }^{\circ}$ 8.177/91, assim tratou sobre o FGTS:

Art. 17. A partir de fevereiro de 1991, os saldos das contas do Fundo de Garantia por Tempo de Serviço (FGTS) passam a ser remunerados pela taxa aplicável à remuneração básica dos depósitos de poupança com data de aniversário no dia 1, observada a periodicidade mensal para remuneração (Grifos nossos).

Esse artigo reitera a normatividade da remuneração do FGTS nos mesmos termos da poupança.

O art. 12 dessa mesma lei assim determina sobre a remuneração da poupança:

Art. 12. Em cada período de rendimento, os depósitos de poupança serão remunerados:

I - como remuneração básica, por taxa correspondente à acumulação das TRD, no período transcorrido entre o dia do último crédito de rendimento, inclusive, e o dia do crédito de rendimento, exclusive;

Ou seja, os valores do FGTS seriam atualizados via TRD, Taxa Referencial Diária, que refere-se ao valor diário à distribuição pro rata dia da TR fixada para o mês corrente, divulgado 
pelo Banco Central.

Já a TR, taxa referencial, seria calculada a partir da remuneração mensal média líquida de impostos, dos depósitos a prazo fixo captados nos bancos comerciais, bancos de investimentos, bancos múltiplos com carteira comercial ou de investimentos, caixas econômicas, ou dos títulos públicos federais, estaduais e municipais, de acordo com metodologia a ser aprovada pelo Conselho Monetário Nacional.

A Lei $n^{\circ} 8.660 / 93$ trouxe novos critérios para a fixação da Taxa Referencial, vindo a extinguir a TRD. Em seu art. $7^{\circ}$ determina que a remuneração básica, dos valores a título de poupança, será a Taxa Referencial relativa à respectiva data de aniversário.

De tal sorte, a partir de 31 de maio de 1993 (data da publicação da Lei nº 8.660/93), não só a poupança, mas também os valores do FGTS passaram a ser atualizados a partir da Taxa Referencial (TR).

O problema, suscitado em meados de 2013, fora que tal correção dos depósitos fundiários, baseados na taxa referencial, não correspondia a desvalorização causada pela perda inflacionária, suscitando a hipótese de que fosse utilizado outros índices para correção, que de fato correspondesse a perda do poder de compra da moeda.

Fazendo uso de uma metodologia de análise qualitativa e utilizando-se os métodos de abordagem hipotético-dedutivos de caráter descritivo e analítico, buscar-se-á fazer uma apreciação sobre adequação do uso da Taxa Referencial para correção monetária dos valores depositados da conta do FGTS.

\section{O QUESTIONAMENTO SOBRE A CORREÇÃO DO FGTS NOS TRIBUNAIS}

O problema, ora versado nesse trabalho, foi posto em pauta para que o poder judiciário se manifestasse. Arisca-se a dizer que o entendimento a ser construído pela jurisprudência brasileira, sobre o assunto, talvez seja o de maior efeito impactante e sensível da atualidade, tendo em vista afetar algo em torno de 45 milhões de trabalhadores (Laporta, 2014).

A Caixa Econômica Federal estima mais de 50 mil ações já demandadas ao judiciário pleiteando o uso de outro índice de correção dos valores depositados para o FGTS (Laporta, 2014); (Jardim, 2014).

A própria Justiça Federal do Rio Grande do Sul, em decorrência da quantidade de ações, chegou a disponibilizar um programa (FGTS-net e FGTS-web) ${ }^{6}$ que efetua o cálculo da correção monetária do FGTS, para auxiliar os demandantes, na feitura do pedido, no que tange a quantificar os valores devidos.

De tal sorte, buscar-se-á aferir o andamento dos principais processos no país.

${ }^{6}$ FGTS-NET. Disponível em: www2.jfrs.jus.br/?page_id=9918. Acesso em: 10 de julho de 2014. 


\subsection{AÇÃO CIVIL PÚBLICA - JUSTIÇA FEDERAL DO RIO GRANDE DO SUL}

No dia 03 de fevereiro de 2014, a Defensoria Pública da União, ajuíza a ação civil pública de $n^{0}$ 5008379-42.2014.404.7100, na Justiça Federal do Rio Grande do Sul, contra a Caixa Econômica Federal, demandando o recálculo da "correção dos depósitos das contas do FGTS a partir de janeiro de 1999, substituindo-se a atualização da TR ou pelo INPC, ou IPCA-E, ou o índice utilizado pelo STF ... ou outro que melhor reflita a inflação”.

E além disso solicitou:

(...) que o recálculo determinado seja realizado nas contas, cujos depósitos não tenham sido levantados até a data da recomposição, assim como no caso de depósitos levantados entre janeiro/1999 até a data da recomposição, tanto na pessoa dos titulares das contas, como, em caso de falecimento, aos seus dependentes legais ou sucessores (...).

No dia 05 de fevereiro de 2014, o juiz da $4^{\circ}$ Vara Federal de Porto Alegre, oferta o despacho inicial, recebendo a ação, reconhecendo a sua abrangência ao âmbito nacional, baseando-se em precedentes do Superior Tribunal Federal - STF e do Superior Tribunal de Justiça - STJ, que conhecem a possibilidade de atribuição da eficácia nacional em relação a decisões referentes a ação civil pública, não subsistindo, ao caso, o conteúdo normativo equivocado do art. 16 da Lei $\mathrm{n}^{\circ} 7 \cdot 347 / 85$, que limita os efeitos aos limites da competência territorial do órgão prolator 7 .

Pondera, ainda, que a matéria tratada constitui direito coletivo stricto senso, amoldado aos termos do art. 81, parágrafo único, II, do Código de Defesa do Consumidor ${ }^{8}$, o que de tal sorte, acarreta a necessidade de uma decisão uniforme para todos os casos do país, em face da peculiaridade do direito lesionado "não se podendo conceber que parte dos titulares de contas tenha direito à substituição do índice de correção e outros não" 9

Esse processo encontra-se, hoje, suspenso, em conformidade com decisão proferida do STJ (Resp n ${ }^{0}$ 1.381.683/PE), como explicitado na decisão interlocutória de 05 de março de $2014^{10}$.

\subsection{SUPERIOR TRIBUNAL DE JUSTIÇA (STJ) - RECURSO ESPECIAL N ${ }^{\circ} 1.381 .683 / \mathrm{PE}$}

A situação processual que ensejou o conteúdo jurídico do Recurso Especial ${ }^{\circ} 1.381 .683$, a ser decidido pelo STJ, tem o seu preludio numa ação coletiva de $n^{0}$ ooo8182-42.2011.4.05.8300, tendo por autor o Sindicato dos Trabalhadores na Indústria de Petróleo no Estado de Pernambuco

\footnotetext{
${ }^{7}$ Lei no 7.347/85. Art. 16. A sentença civil fará coisa julgada erga omnes, nos limites da competência territorial do órgão prolator, exceto se o pedido for julgado improcedente por insuficiência de provas, hipótese em que qualquer legitimado poderá intentar outra ação com idêntico fundamento, valendo-se de nova prova.

${ }^{8}$ Código de Defesa do Consumidor. Art. 81, parágrafo único, II - interesses ou direitos coletivos, assim entendidos, para efeitos deste código, os transindividuais, de natureza indivisível de que seja titular grupo, categoria ou classe de pessoas ligadas entre si ou com a parte contrária por uma relação jurídica base;

${ }^{9}$ Justiça Federal do Rio Grande do Sul. Ação Civil Pública Decisão no 5008379-42.2014.404.7100 Decisão interlocutória, p. 8. Disponível em: eproc.jfrs.jus.br/eprocV2/. Acesso em: 10 de julho de 2014.

${ }^{10}$ Disponível em: eproc.jfrs.jus.br/eprocV2/. Acesso em: 10 de julho de 2014.
} 
e da Paraíba, distribuído no dia 17 de junho de 2011, na Justiça Federal de Pernambuco.

No dia 31 de janeiro de 2012, o juiz titular da $5^{\circ}$ Vara Federal, oferta a sentença de mérito ${ }^{11}$, não acatando o pleito do sindicato, no que tange a correção do FGTS, em face de um outro índice, que não a TR, que corrigisse os valores a partir dos índices inflacionários oficiais, argumentando que "tal como ocorre para o período posterior à edição da Lei n 7.839/1989, não há qualquer dispositivo legal ou constitucional impondo uma correlação entre a correção aplicada e a inflação oficial divulgada pelo Governo Federal”"

A Caixa Economia Federal, irresignada, pois no que tange a outra demanda, pleiteada na mesma ação, ter sido desfavorável, adentra com uma apelação a sentença, instando o Tribunal Federal da $5^{\circ}$ região, e o Sindicato com um recurso adesivo, sendo distribuída no dia 06 de junho de 2012.

Segue o dispositivo da sentença recorrida:

Posto isso, julgo procedente em parte o pedido, para condenar a CAIXA a revisar os cálculos de correção das contas de FGTS dos substituídos, aplicando os índices de atualização monetária (expurgos inflacionários) correspondentes a 18,02\% (LBC de Junho de 1987),42,72\% (IPC de Janeiro de 1989),44,80\% (IPC de Abril de 1990),5,38\% (BTN de Maio de 1990) e 7,00\% (TR de Fevereiro de 1991), respeitando-se os percentuais efetivamente já aplicados e ressalvandose a efetiva titularidade de conta de FGTS nos respectivos períodos, devendo as quantias serem atualizadas de acordo com a sistemática de correção própria das contas de FGTS (aplicação da TR mais juros de $3 \%$ ao ano) até a data da citação, a partir de quando deverá incidir apenas a SELIC, como sucedânea da atualização e dos juros de mora, tudo a ser devidamente apurado quando do cumprimento do julgado, proferindo, assim, julgamento com resolução de mérito, nos termos do artigo 269, inciso I, do Código de processo Civil - $\mathrm{CPC}^{13}$.

No dia 27 de setembro de 2012, a primeira turma do tribunal aprecia o mérito da apelação e do recurso adesivo, negando de forma unânime os dois pleitos, pronunciando-se:

ADMINISTRATIVO. FGTS. APELAÇÃO. RECURSO ADESIVO. PEDIDO PARA AFASTAMENTO DA TR NA CORREÇÃO DOS SALDOS DAS CONTAS VINCULADAS AO FGTS. PEDIDO PARA REPOSIÇÃO DOS ÍNDICES DE INFLAÇÃO DIVULGADOS PELO GOVERNO FEDERAL. REAJUSTE DAS CONTAS FUNDIÁRIAS POR LEGISLAÇÃO ESPECÍFICA. APLICAÇÃO DOS EXPURGOS INFLACIONÁRIOS PREVISTOS NA SÚMULA 252 DO STJ. SENTENÇA MANTIDA.

\footnotetext{
${ }_{11}$ Publicação no Diário Oficial do Estado de Pernambuco, em 03 de fevereiro de 2012.

${ }^{12}$ Disponível em: www.jfpe.jus.br/consultaProcessos/cons_procs.asp. Acesso em: 10 de julho de 2014.

${ }^{13}$ Disponível em: www.jfpe.jus.br/consultaProcessos/cons_procs.asp. Acesso em: 10 de julho de 2014.
} 
...

7. A correção monetária aplicável aos saldos depositados nas contas vinculadas ao FGTS nunca estiverem equiparadas aos mesmos índices adotadas pelo governo para medir a inflação do período, razão por que, no caso dos autos, prevalecem os índices descritos nas Leis que disciplinaram o Fundo de Garantia por Tempo de Serviço-FGTS, ou seja, as Leis $\mathrm{n}^{\mathrm{o}} \mathrm{S} 5.107 / 66,7.839 / 89$ e 8036/90 ${ }^{14}$.

Em decorrência de mais uma decisão desfavorável, vem, agora, o Sindicato dos Trabalhadores na Indústria de Petróleo no Estado de Pernambuco e da Paraíba impetrar o Recurso Especial $n^{0}$ 1.381.683/PE, o qual fora autuado, no STJ, no dia 20 de maio de 2013 , tendo por relatoria o Ministro Benedito Gonçalves.

Na decisão monocrática, de 21 de fevereiro de 2014, do ministro supra, aferindo a multiplicidade de recursos a respeito da matéria, suspende o processamento dos demais recursos, em andamento, no âmbito da justiça federal, instando que a controvérsia seja dirimida no âmbito da Primeira Seção do STJ ${ }^{15}$.

Acatando pleito da Caixa Econômica Federal, a qual afirma sobre a existência de mais de 50 mil ações dessa natureza, o ministro relator, buscando evitar a insegurança jurídica, em decisão monocrática, do dia 26 de fevereiro de 2014, estende os efeitos suspensivos a todos os processos em trâmite nas instâncias da Justiça comum, estadual e federal, inclusive Juizados Especiais cíveis e as respectivas Turmas ou Colégios Recursais ${ }^{16}$.

Até o momento ainda não foi colocado o Respectivo Recurso Especial em pauta de julgado.

\subsection{AÇÃO DIRETA DE INCONSTITUCIONALIDADE No 5090}

No presente ano é interposta uma ação direta de inconstitucionalidade, $\mathrm{ADI} \mathrm{n}^{\circ}$ 5090, pelo Partido Solidariedade, a qual leva o problema para apreciação do Superior Tribunal Federal STF, sendo distribuída no dia 12 de fevereiro, tendo como relator o ministro Roberto Barroso.

A peça exordial apresentada, pelo Partido Solidariedade, tem por elementos balizadores que justificam a inconstitucionalidade do art. 13, caput, da Lei Federal n ${ }^{\circ}$ 8.036/1990 e do art. 17, caput da Lei Federal no 8.177/1991, os quais impõe a correção do FGTS pela Taxa Referencial (TR), a transgressão ao direito de propriedade ${ }^{17}$, direito do FGTS $^{18}$ e da moralidade administrativa ${ }^{19}$.

\footnotetext{
${ }^{14}$ Disponível em: www.trf5.jus.br/data/2012/09/00081824220114058300 20120927 4643849.pdf. Acesso em: 10 de julho de 2014.

${ }^{15}$ STJ. Recurso Especial no 1.381.683/PE. Decisão Monocrática. Publicado no dia 21 de fevereiro de 2014. Disponível em: https://ww2. stj.jus.br/processo/revista/documento/mediado/?componente=MON\&sequencial=33885054\&num_registro=201301289460\&data= 20140221\&formato=PDF. Acesso em: 10 de julho de 2014.

${ }^{16}$ STJ. Recurso Especial no 1.381.683/PE. Decisão Monocrática. Publicado no dia 26 de fevereiro de 2014. Disponível em: https:// ww2.stj.jus.br/processo/revista/documento/mediado/?componente=MON\&sequencial=34017300\&num_registro=201301289 460\&data=20140226\&formato=PDF. Acesso em: 10 de julho de 2014.

${ }^{17}$ Art. 5ㅇ, XXII da Constituição Federal.

${ }^{18}$ Art. 70, III da Constituição Federal.

${ }^{19}$ Art. 37, caput da Constituição Federal.
} 
A Caixa Econômica Federal, o Banco Central do Brasil e a Defensoria Pública da União ingressarão, na respectiva ADI, como amicus curiae.

O atual Procurador-Geral da República, Rodrigo Janot Monteiro de Barros, já se manifestou nos autos, tendo emitido um parecer pelo não conhecimento da ação, e em caso de conhecimento, pela improcedência do pedido.

Foi suscitado no parecer pelo não conhecimento da ação devido à ausência de possibilidade jurídica do pedido, tendo em vista que a própria lei no 8.177/91 extinguiu o índice do BTN, dando lugar a TR. Em caso da declaração de inconstitucionalidade, não subsistiria índice passível de correção o que geraria uma lacuna normativo.

Segue os argumentos do Procurador-Geral da República:

Por conseguinte, não existe índice do BTN passível de aplicar a partir de fevereiro de 1991, no lugar da TR, de modo que a declaração de inconstitucionalidade pretendida geraria vácuo normativo completo, não passível de complementação por meio do efeito repristinatório.

Portanto, é impossível a declaração de inconstitucionalidade dos dispositivos, com efeitos ex tunc ou ex nunc, dadas a extinção do BTN e a incompetência técnica do STF para definição de índice inflacionário válido a partir da data da decisão ${ }^{20}$.

No que tange o mérito, disserta pelo não acatamento do pedido, com fulcro de que o direito fundamental, albergado na Constituição, é a indenização por tempo de serviço e não o fundo em si $^{21}$; inexistência de violação do princípio da moralidade administrativa, por parte da Caixa Econômica Federal, por apropriação da diferença entre a inflação e a TR, pois a mesma é mera agente operadora da aplicação dos recursos do FGTS, não lhe assistindo dispor dos recursos em seu benefício, além de não possuir atribuições para definir índices de correção monetária a que devam ser utilizadas ${ }^{22}$; inexistência de violação do direito à propriedade, visto a inexistência de regramento constitucional que constituía o dever de atualização monetária em face de indexador que preserve o valor real da moeda, o que impossibilita o Poder Judiciário de determinar certo índice, cabendo, sim, ao legislador ${ }^{23}$.

Destaca-se a seguinte passagem do parecer do Procurador-Geral da República, onde arrazoa pela não violação do direito constitucional da propriedade, como alegado na exordial:

\footnotetext{
${ }^{20}$ Parecer no 3.458 da Procuradoria Geral da República, na Ação direta de inconstitucionalidade, p. 26. Disponível em: www.stf. jus.br/portal/processo/verProcessoPeca.asp?id=4565011\&tipoApp=.pdf. Acesso em: 10 de julho de 2014.

${ }^{21}$ Parecer no 3.458 da Procuradoria Geral da República, na Ação direta de inconstitucionalidade, p. 29. Disponível em: www.stf. jus.br/portal/processo/verProcessoPeca.asp?id=4565011\&tipoApp=.pdf. Acesso em: 10 de julho de 2014.

${ }^{22}$ Parecer no 3.458 da Procuradoria Geral da República, na Ação direta de inconstitucionalidade, p. 34. Disponível em: www.stf. jus.br/portal/processo/verProcessoPeca.asp?id=4565011\&tipoApp=.pdf. Acesso em: 10 de julho de 2014.

${ }^{23}$ Parecer no 3.458 da Procuradoria Geral da República, na Ação direta de inconstitucionalidade, p. 49. Disponível em: www.stf. jus.br/portal/processo/verProcessoPeca.asp?id=4565011\&tipoApp=.pdf. Acesso em: 10 de julho de 2014.
} 


\begin{tabular}{c}
\hline ROCCO ANTONIO RANGEL ROSSO NELSON - MARCOS VASCONCELOS CORREIA \\
$158<\quad$ FUNDO DE GARANTIA POR TEMPO DE SERVIÇO (FGTS) - EM BUSCA DA CORREÇÃO “JUSTA”. \\
Pags. $146-163$ \\
\hline
\end{tabular}

\begin{abstract}
Além do direito de propriedade, a Constituição também protege a estabilidade do sistema econômico brasileiro, indiscutivelmente vinculada à estabilidade monetária. A moeda, além de seu nítido valor econômico stricto sensu, apresenta relevante valor social e político e costuma servir de instrumento da própria soberania nacional, exercida pelos poderes republicanos constituídos. A validade dos dispositivos legais impugnados decorre da prerrogativa constitucional de o Estado instituir políticas econômicas ativas, mediante leis editadas nos limites da competência legislativa para dispor sobre Direito Monetário ${ }^{24}$ (Grifos nossos).
\end{abstract}

A presente ação direta de inconstitucionalidade, encontra-se concluso ao ministro relator, desde 29 de maio de 2014, tendo sido está a última movimentação processual25.

\title{
3. EM DEFESA DE UMA “JUSTA” CORREÇÃO
}

Coaduna-se com os argumentos em favor do direito à correção dos valores depositados na conta do FGTS a partir de um índice que reflita a perda do poder de compra da moeda em face da inflação.

Se o objetivo da correção é recuperar o poder de compra, tentando repor, periodicamente, o valor deteriorado com a inflação, a fim de compensar a perda real do dinheiro, resulta que a aplicação da TR deixa a desejar porque não reflete essa realidade, não tendo acompanhado nenhum índice de correção, embora seja certo que, no Sistema Financeiro Nacional existe um elenco bastante expressivo de operações que remunera, como, dentre outros, os contratos do Sistema Financeiro da Habitação, caderneta de poupança, crédito educativo, Fies e os depósitos judiciais (Franco Filho, 2014, p. 194).

Não se pode perfilar com a justificativa da não concessão do direito a correção, advogando a legalidade e constitucionalidade da TR baseado no raciocínio de que não há dispositivo legal que obrigue a correção por um índice que recomponha as perdas inflacionárias.

Afira-se que o FGTS constitui, em sua essência, em uma parcela salarial do trabalhador, no qual, em decorrência da compulsoriedade da lei, é destinado a um fundo, onde o trabalhador

\footnotetext{
${ }^{24}$ Parecer no 3.458 da Procuradoria Geral da República, na Ação direta de inconstitucionalidade, p. 48. Disponível em: www.stf. jus.br/portal/processo/verProcessoPeca.asp?id=4565011\&tipoApp=.pdf. Acesso em: 10 de julho de 2014.

25 Disponível em: redir.stf.jus.br/estfvisualizadorpub/jsp/consultarprocessoeletronico/ConsultarProcessoEletronico. jsf?seqobjetoincidente=4528066. Acesso em: 10 de julho de 2014.
} 
não possui livre acesso para saque, podendo ser movimentado, apenas, em situações excepcionalíssimas.

"É importante salientar que os depósitos do FGTS constituem um plus salarial e não um desconto na remuneração do operário, como acontece com as contribuições previdenciárias do empregado" (Cairo Jr, 2011, p. 678).

"Portanto, os depósitos fundiários assemelham-se ao salário, mais precisamente aos complementos salariais ou sobre-salário, de natureza diferida, ou seja, devido após o implemento de determinada condição estabelecida em lei” (Cairo Jr, 2011, p. 680).

Com o tempo, verificou-se que os levantamentos do Fundo eram muito condicionados, que as vultosas importâncias recolhidas em seu nome e os rendimentos de sua aplicação no mercado permaneciam e permanecem detidas nas mãos dos 6rgãos ou do administrador do Fundo, no caso, a Caixa Econômica Federal, que deles dispõem como se fossem próprios ou deles se servem, na maioria das vezes, para suprir o caixa do Governo para a cobertura de "déficits" orçamentários ou de remanejamento de dinheiros em situações imprevistas ou difíceis da administração pública” (Vilhena, 1992, p. 164).

Ou seja, esses valores, recolhidos a título de FGTS, constitui parcela da propriedade dos trabalhadores, cujo uso e gozo estão restringidos, ficando sobre a guarda e administração da Caixa Econômica Federal - CEF.

Destarte, conceber que essa propriedade, constituída pelo saldo do FGTS, no qual o trabalhador tem o seu acesso limitado ao uso, podendo passar décadas antes que surja situação, segundo os moldes legais, que eleja-o ao saque, continue sendo corrigido a partir da TR, o qual não corresponde a real corrosão monetária ocasionada pela inflação, vai de encontro ao sentimento de justiça, afigurando-se uma verdadeira conduta confiscatória perpetrada em desfavor de 45 milhões de trabalhadores.

Em um Estado de Direito, cuja Constituição prescreve a proteção a propriedade e de um plexo de direitos fundamentais sociais, os quais constituem um mínimo existencial de direitos ao trabalhador, não se pode admitir a pratica confiscatória estatal quando da não justa remuneração dos saldos do FGTS.

As alegações de que em caso de reconhecimento do direito a correção a partir de índices como o INPC, isso possa deflagrar instabilidade econômica e comprometer a política habitacional chegar a ser imoral e aviltante, pois quer-se transferir a conta e a responsabilidade da saúde econômica do Brasil em desfavor do trabalhador que tem o seu patrimônio alijado.

Evidente que não deve prosperar argumento com o desequilíbrio do Sistema Financeiro Nacional, e nem possíveis impactos na política econômica. Será 
falacioso dizer que o principal prejudicado será o trabalhador. Ora, seja isolada, seja conjuntamente, os trabalhadores estão sendo vítimas de uma redução no direito que lhes é devido à medida em que, ao contrário de terem repostas as perdas decorrentes da inflação, ficam sem nada haver limitados apenas a irrisórios juros que não refletem a verdadeira finalidade do FGTS (Franco Filho, 2014, pp. 192-193).

Condicionar o reconhecimento ou não da violação de um direito a fatores políticos e econômicos e subverter a lógica do sistema jurídico, gerando uma disfunção interna e comprometendo sua autonomia e sua finalidade.

É de importância nefrálgica e de uma clareza solar as palavras do professor Campilongo (2011): "O direito positivo moderno trata de todo e qualquer tema ou caso, desde que juridicamente. A partir desse tratamento constrói sua diferença com outros sistemas e opera com elevado grau de complexidade interna" (p. 88).

Sendo assim, a lógica sistêmica jurídica opera em termos exclusivamente jurídicos, a partir de uma linguagem binária lícito/ilícito (Campilongo, 2011). A partir disso tem o direito a função única de garantir uma expectativa de direito, normativa (Campilongo, 2011).

Com isso extrai-se a seguinte premissa: o sistema jurídico distingue-se do sistema político e do sistema econômico, o qual possui uma outra lógica, uma outra linguagem, com outras funções (Campilongo, 2011).

A inobservância da premissa supra acarreta atribuir ao direito funções além de suas possibilidades ${ }^{26}$, vindo o mesmo a ser reduzido como técnica do sistema político ou econômico ${ }^{27}$, quedando-se, assim, as fronteiras entre os sistemas e consequentemente anulando ou corrompendo os limites impostos pelo direito, aos demais sistemas. Ter-se-ia a politização do direito e a mercantilização do direito (Campilongo, 2011).

“... A política não pode operar economicamente. O mesmo se diga do direito...” (Campilongo, 2011, p. 109).

É ululante que o sistema operativo fechado, a qual é o direito, não possui controle sobre os sistemas que estão em seu entorno (politico, econômico, das ciências). Da mesma forma, esse ambiente externo ao direito não conseguem suprir o conteúdo típico e único do direito.

Como arremata o professor Campilongo (2011):

... A unidade, os limites e a especificidade do sistema jurídico são construídos a partir de dentro do próprio sistema jurídico, não são oferecidas pela economia nem pela ciência. A unidade do sistema jurídico é resultante do funcionamento do próprio

\footnotetext{
26 “Transformar o Direito é o que está ao alcance do sistema jurídico. Pretende transformar, com a norma jurídica, a realidade econômica me parece um ambição, um imperialismo que vai além das possibilidades do Direito" (Campilongo, 2011, p. 94).

27 "Questão interessante e de grande importância para a presente reflexão é o fato de que, a nosso ver, dentre os ramos da ciência jurídica o Direito do Trabalho é, talvez, desde suas origens, o mais interdependente da Economia e dos ciclos econômicos, com todas as suas consequências no mercado de trabalho" (Scabin, 2013, p. 35).
} 
sistema jurídico. A diferenciação entre o sistema jurídico, a ciência, a economia, a política, é uma diferenciação construída no interior do Direito. Isto limita muito o socorro que eu possa ter - com critérios hermenêuticos, ou, pelo menos, com critérios juridicamente admissíveis - de elementos exteriores ao sistema jurídico (p. 94).

A partir dessa visão de unidade do sistema jurídico torna-se um ato atentatório a base lógica do direito negar o direito a justa correção dos valores fundiários, preservando assim, o direito de propriedade dos trabalhadores, a partir de uma externalidade econômica, no qual estar-se a transferir o risco, o custo e responsabilidade por tal fator ao sujeito hipossuficiente, os milhares de trabalhadores brasileiros.

\section{CONSIDERAÇÕES FINAIS}

No bojo do conteúdo apresentado, não há dúvidas de que o fundo de garantia por tempo de serviço - FGTS constitui-se em um dos direitos fundamentais do trabalhador, assim consagrado na Constituição Federal de 1988.

Aqui, nesse trabalho, perfilha-se o entendimento de que os saldos fundiários devem ser atualizados a partir de índices que reflitam a corrosão da moeda, em decorrência da inflação, não se constituindo a Taxa Referencial índice com tal desiderato.

A matéria em apreço tem que ser tratada pelo viés da lógica jurídica, não podendo assim comprometê-la em face dos fatores econômicos, sob pena que desvirtuar a função do direito e, casuisticamente, alijar milhares de trabalhadores do uso de um instrumento que preserve, adequadamente, a sua propriedade, esta refletida, no caso, nos valores monetários depositados a título de FGTS, o qual se constitui num verdadeiro salário diferido.

Fica-se, então, no aguardo do desfecho da matéria pelo Superior Tribunal Federal - STF, na esperança de que os direitos dos trabalhadores sejam salvaguardados e que mais de uma década de perda patrimonial seja recuperado.

\section{REFERÊNCIAS BIBLIOGRÁFICAS}

Barros, A. M. (2011). Curso do Direito do Trabalho (7 $7^{\circ}$ ed.). São Paulo: LTR.

Cairo Jr, J. (2011). Curso do direito do trabalho (6º ed.). Salvador: Juspodivm. 


\begin{tabular}{c}
\hline ROCCO ANTONIO RANGEL ROSSO NELSON - MARCOS VASCONCELOS CORREIA \\
$162<\quad$ FUNDO DE GARANTIA POR TEMPO DE SERVIÇO (FGTS) - EM BUSCA DA CORREÇÃO “JUSTA”. \\
Pags. 146 - 163 \\
\hline
\end{tabular}

Campilongo, C. F. (2011). Direito e diferenciação social. São Paulo: Saraiva.

Canotilho, J. J., Leoncy, L. F., Mendes, G. F., Sarlet, I. W., \& Streck, L. L. (2013). Comentários à Constituição do Brasil. São Paulo : Saraiva.

Cassar, V. B. (2010). Princípios Trabalhistas, Novas Profissões, Globalização da Economia e Flexibilização das Normas Trabalhistas. Rio de Janeiro: Impetus.

Cassar, V. B. (2011). Direito do Trabalho ( $5^{\circ}$ ed.). Rio de Janeiro: Impetus.

Delgado, M. G. (2011). Curso do Direito do Trabalho (10 ed.). São Paulo: LTR.

Franco Filho, G. d. (março-abril de 2014). Revisão de FGTS: correção de uma injustiça. Revista de Direito do Trabalho, pp. 187-194.

Jardim, L. (02 de abril de 2014). MPF dá parecer favorável à correção do FGTS pelo índice da inflação. Acesso em 10 de junho de 2014, disponível em UOL Notícias: acritica.uol.com.br/ noticias/Procurador-Fundo-Garantia-Tempo-Servico_o_1112888736.html

Laporta, T. (o9 de abril de 2014). Correção do FGTS: União diz que ações iludem trabalhadores. Acesso em 10 de julho de 2014, disponível em IG São Paulo: economia.ig.com. br/financas/2014-04-09/correcao-do-fgts-uniao-diz-que-acoes-iludem-trabalhadores.html

Martins, S. P. (2005). Direito do trabalho. São Paulo: Atlas.

Martins, S. P. (2009). Flexibilização das Condições de trabalho (4º ed.). Sâo Paulo: Atlas.

Scabin, R. F. (2013). O Direito do Trabalho como limitador do poder econômico. Em J. d. Cavalcante, \& M. A. Villatore, CLT 70 anos de consolidação: uma reflexão social, econômica e jurídica. São Paulo: Atlas.

Vilhena, P. E. (out/dez de 1992). O novo FGTS. Percussões constitucionais. Revista de informação legislativa, 116, pp. 163-176. 


\section{CURRICULUM VITAE}

\section{Rocco Antonio Rangel Rosso Nelson}

Especialista em Direito e Cidadania pela Escola Superior do Ministério Público. Especialista em Direito Penal e Criminologia pela Universidade Potiguar. Mestre em Direito Constitucional pela UFRN. Ex-professor do curso de direito do Centro Universitário FACEX. Professor de Direito do Instituto Federal do Rio Grande do Norte - IFRN.

rocconelson@hotmail.com

\section{Marcos Vasconcelos Correia}

Graduado em Administração pela Unihristus - CE. Especialista em Marketing pela Universidade Federal do Ceará - UFC. Mestre em Administração pela Universidade Federal do Ceará - UFC. Professor de Administração e Cooperativismo do Instituto Federal do Rio Grande do Norte IFRN.

marcos.adm.vascon@gmail.com 